\title{
The cost of freezing general practice
}

\section{Even though \\ the rebate \\ reduction has}

been retracted

... the freeze

may still force

GPs who

currently bulk

bill to charge

copayments

\begin{abstract}
Christopher Harrison
BPsy(Hons), MSocHealth GP services in December 2003 to $84.0 \%$ in September $2014 .^{5}$
\end{abstract}

Clare Bayram BAppSc(HIM)(Hons), PhD

Graeme C Miller MBBS, PhD, FRACGP

Helena C Britt $\mathrm{BA}, \mathrm{PhD}$

University of Sydney, Sydney, NSW.

christopher.harrison@ sydney.edu.au

doi: 10.5694/mjal5.00182

Online first 23/03/15
A ustralia's universal health insurance scheme, Medicare, began as Medibank in 1975 and aimed to provide "universal coverage of the population, equitable distribution of costs, [and] administrative simplicity". ${ }^{1}$ Funded by the Australian Government, Medicare reimburses general practitioner services on a fee-for-service basis. General practice is the most widely used health service; $85 \%$ of the population see a GP in any given year. ${ }^{2}$

Currently, patients using GP services are either bulk billed or privately billed. Bulk-billed patients have no out-of-pocket expenses, and the GP receives a rebate directly from Medicare. Privately billed patients pay for their services at the fee set by the GP and claim the eligible rebate from Medicare.

In 1978, the rebate was decreased from $85 \%$ of the Medicare schedule fee to $75 \%$, and bulk-billing was restricted to pensioners and socially disadvantaged people. Since then, federal governments have encouraged bulkbilling. In 1984, the rebate returned to $85 \%$ and bulk-billing was reintroduced for all patients. In 2004, incentives were introduced for GPs to bulk bill concessional patients (ie, children $<16$ years of age or Commonwealth concession card holders). ${ }^{3}$ In 2005, the rebates were increased to $100 \%{ }^{4}$ These measures made it financially viable for many GPs to bulk bill all patients, and bulk-billing increased from $66.5 \%$ of all Medicare-claimed

The 2014-15 federal Budget proposed the introduction of a $\$ 7$ patient copayment for GP, pathology and imaging services; and an increase in the copayment for subsidised prescribed medications. The financial impact of these proposals was shown to be highest among patients with a Commonwealth concession card. ${ }^{6}$

Facing strong opposition, the government withdrew the policy in December 2014, and replaced it with three new policies. The first, a

Abstract

Objectives: We aimed to assess the effect on general practitioners' income, and the amount of any copayment required for GPs to recoup lost income, of two policies (individually and combined) proposed by the Australian Government: a continued indexation freeze of Medicare schedule fees; and a $\$ 5$ rebate reduction (now retracted).

Design, setting and participants: Analysis of data from the Bettering the Evaluation and Care of Health (BEACH) program, a continuous crosssectional, national study of GP activity in Australia. We used data for April 2013 to March 2014 on direct encounters between patients and GPs for which at least one Medicare Benefits Schedule or Department of Veterans' Affairs general practice consultation item was claimable.

Main outcome measures: The reduction in GP rebate income due to the policies and the size of any copayment needed to address this loss.

Results: The $\$ 5$ rebate reduction would have reduced GPs' income by $\$ 219.53$ per 100 consultations. This would have required a $\$ 4.81$ copayment at all non-concessional patient consultations to recoup lost income. The freeze would cost GPs $\$ 384.32$ in 2017-18 dollars per 100 consultations, requiring an $\$ 8.43$ copayment per non-concessional patient consultation. Total estimated loss in rebate income to GPs would have been $\$ 603.85$ in 2017-18 per 100 encounters, a reduction of 11.2\%. The non-concessional consultation copayment required to cover lost income from both policies would have been $\$ 7-\$ 8$ in 2015-16, and \$12-\$15 by 2017-18.

Conclusion: If both policies had gone ahead, GPs would have needed to charge substantially more than the suggested \$5 copayment for consultations with non-concessional patients in order to maintain 2014-15 relative gross income. Even though the rebate reduction has been retracted, the freeze will have greater impact with time - nearly double the amount of the rebate reduction by 2017-18. For economic reasons, the freeze may still force GPs who currently bulk bill to charge copayments.

10-minute minimum time for standard GP consultations, was retracted in January 2015. The second, a \$5 reduction in the Medicare rebate for "common GP consultations" for nonconcessional patients to commence 1 July 2015, was retracted in March 2015. The government had suggested GPs could charge a $\$ 5$ copayment to non-concessional patients to cover the rebate reduction. While referred to as a copayment, it was technically a gap payment where GPs privately charged their patients and the patients claimed the lowered Medicare rebate.

The third policy was a continuation of the indexation freeze for all Medicare schedule fees until July $2018^{7}$ (henceforth referred to as the freeze). The $\$ 5$ copayment would not have covered income lost through the freeze. Using publicly available data, Duckett calculated the combined effect of the second and third policies, estimating they would reduce GPs' rebate income by $10.6 \%$ by $2017-18$ (assuming a consumer price index [CPI] of $2.5 \%$ ). To cover all the costs generated by these two policies, Duckett hypothesised that GPs may move to charge non-concessional patients a copayment similar to the gap payment currently charged privately by some GPs (\$30-\$40), ${ }^{8}$ well above the $10.6 \%$ reduction.

The study we report here was conducted in February 2015, before the retraction of the $\$ 5$ rebate reduction. Using data that measured GP clinical activity, we aimed to assess the effect of the indexation freeze and the (now retracted) \$5 rebate reduction on a GP's Medicare income for an average 100 eligible consultations; and, assuming all concessional patients are bulk billed, we aimed to estimate for all consultations with non-concessional patients the patient copayment required for GPs to recoup the lost Medicare rebate income. 


\section{Bettering the Evaluation and Care of Health (BEACH)}

We analysed data from the BEACH program, from April 2013 to March 2014, inclusive. BEACH is a continuous cross-sectional, national study of the content of GP-patient encounters in Australia. Every year, about 1000 ever-changing randomly selected GPs each record details of 100 consecutive encounters with consenting patients, on structured paper forms. $\mathrm{BEACH}$ methods are described in detail elsewhere. ${ }^{2}$

The age-sex distribution of patients at Medicare-claimable encounters in the $\mathrm{BEACH}$ program is representative of that of patients at all GP services claimed through Medicare. $^{2}$

Ethics approval for the BEACH program was obtained from the University of Sydney Human Research Ethics Committee.

Information recorded for each encounter includes: patient age, and whether he or she holds a Commonwealth concession card or a Department of Veterans' Affairs (DVA) repatriation health card; whether it was a direct consultation (patient was physically seen by the GP); and whether the consultation was intended to be claimable by the GP or patient through Medicare or the DVA (for up to three items) or through another source.

\section{Using BEACH data to assess the effect of proposed policies on GP income}

We limited our analysis to direct encounters for which at least one Medicare Benefits Schedule (MBS) or DVA general practice consultation item was claimable. These account for about $94 \%$ of all recorded encounters, with the other encounters being indirect (eg, by phone), having no charge or being paid through other sources. ${ }^{2}$ Only consultations for which patient age was recorded were included, so patients aged less than 16 years could be identified.

General practice consultation items included were: all surgery consultations, residential aged care facility
(RACF) visits, home and other institution visits, GP mental health care, chronic disease management items, health assessments and case conferences. These were selected and allocated to one of two groups: those with concessional patients (defined as people aged less than 16 years, those holding a Commonwealth concession card and those holding a repatriation health card); and those with non-concessional patients (all other patients).

To estimate the total income claimable from Medicare and DVA items for 100 consultations in the 2014-15 financial year, if all had been bulk billed, we identified the mean rates at which doctors claimed for each item over 100 consultations for concessional patients and non-concessional patients; we then multiplied these rates by the rebatable amount for each item number in the MBS. ${ }^{9}$ These values were summed to provide the total rebate income.

We assumed the bulk-billing GP in our model claimed the bulk-billing incentive item for all concessional patients. We modelled a GP who claimed the urban item (10990) and a GP who claimed the rural item (10991). Based on unpublished BEACH data, when calculating the rebate for visits to RACFs we assumed GPs saw three patients on average, while for visits to other institutions (primarily home visits) we assumed GPs saw one patient. Finally, we assumed that GPs would continue billing a similar distribution of items across the years.

We estimated the expected income for GPs over the 3 years 2015-16 to 201718 by repeating the above calculation for 2014-15 using the reduced rebate for consultation items for non-concessional patients. The items for which the $\$ 5$ reduction applied to non-concessional patients were: all surgery consultations, home and other institution visits and after-hours care. Due to the freeze, our estimate remains constant for all financial years from 2015-16 to 2017-18.

To calculate the loss due to the $\$ 5$ reduction in Medicare rebates, we subtracted the 2014-15 estimate from the 2015-16 estimate.
To measure the effect of the freeze, we calculated the amount GPs would need to earn to maintain an equivalent income rebate level from Medicare and DVA rebates to that of 2014- 15 by multiplying the amount the average bulk-billing GP earned per 100 consultations in $2014-15$ by $2.5 \%$ (the average CPI increase for the previous 5 years, ${ }^{10}$ and the midpoint of the Reserve Bank's target CPI increase of $2 \%-3 \%$ per year ${ }^{11}$ ). The result was multiplied again by the same CPI to get the 2016-17 estimates and again for the 2017-18 estimates. The 2017-18 result was then subtracted from the 2014-15 result, to provide an estimated financial loss due to the freeze.

The size of a copayment required from non-concessional patients to cover this lost income was calculated by dividing the resulting difference in earnings from the policies by the number of non-concessional patients per 100 consultations.

\section{Results}

Between April 2013 and March 2014, there were 95897 patient encounters recorded in the BEACH study, 83510 being direct consultations for which patient age and one or more Medicare or DVA items were recorded. At least one GP consultation item number was recorded at 82211 (98.4\%) of these consultations, including 44723 (54.4\%; $95 \%$ CI, $53.0 \%-55.8 \%$ ) with concessional patients and 37448 (45.6\%; $95 \%$ CI, $44.2 \%-47.0 \%$ ) with non-concessional patients.

\section{$\$ 5$ rebate reduction}

In the 2014-15 financial year, for an average 100 claimable consultations, a bulk-billing-only GP would receive rebates of $\$ 2925.59$ for consultations with concessional patients and \$2072.69 for those with non-concessional patients, a total of $\$ 4998.28$. Applying the $\$ 5$ rebate reduction, the same GP would receive total rebates of $\$ 4778.75$ in the 2015-16 financial year, a decrease of $\$ 219.53$ per 100 average consultations due to the $\$ 5$ reduction for non-concessional patients for most GP items (income from concessional patients 
staying constant). This equated to a $4.3 \%$ decrease in rebate income in 2015-16 and to a $4.0 \%-4.1 \%$ decrease in 2017-18 (Box 1). Averaged across all consultations with non-concessional patients, this equates to a decrease of $\$ 4.81$ per consultation (Box 2).

\section{The freeze}

Assuming a CPI increase of $2.5 \%$ by 2015-16, rebate income would need to increase by $\$ 124.96$ per 100 eligible consultations to match this CPI $(2.5 \%$ of total 2014-15 rebates). This relative loss of $\$ 124.96$ equates to $2.4 \%$ of relative rebate income and $\$ 2.74$ per consultation with non-concessional patients.

From 2014-15 to 2017-18, the estimated CPI increase would be $7.7 \%$. By then, rebate income would need to increase by $\$ 384.32$ per 100 eligible consultations to match this increase. This means the freeze alone would cost GPs $7.1 \%$ (range, $5.8 \%-8.5 \%$ ) of their relative rebate income (Box 1), equivalent to $\$ 8.43$ (range, $\$ 6.71-$ $\$ 10.17)$ per non-concessional patient consultation (Box 2).

As the rural incentive is higher than the urban, GPs claiming the rural bulk-billing incentive item would face a greater relative loss in rebate income due to inflation: 10 cents more per non-concessional patient in 2015-16 (\$2.84) and 29 cents more in 2017-18 (\$8.72).

\section{The policies combined}

Combining the effect of both policies (and assuming an urban setting for the bulk-billing incentive), the total estimated loss in rebate income to GPs per 100 average consultations would be $\$ 603.85$ in 2017-18 - a reduction of $11.2 \%$ (range, $9.9 \%-12.5 \%$ ) (Box 1 ). Assuming concessional patients are bulk billed, if GPs charged a copayment for all non-concessional patient consultations to make up the shortfall in total rebate income, it would need to be \$7-\$8 in 2015-16, and increase to $\$ 12-\$ 15$ by 2017-18 (Box 2).

\section{Discussion}

If both the policies recently proposed by the Australian Government had come into effect as originally

1 Decrease in relative rebate income with either or both of the rebate reduction and indexation freeze policies in place, compared with 2014-15

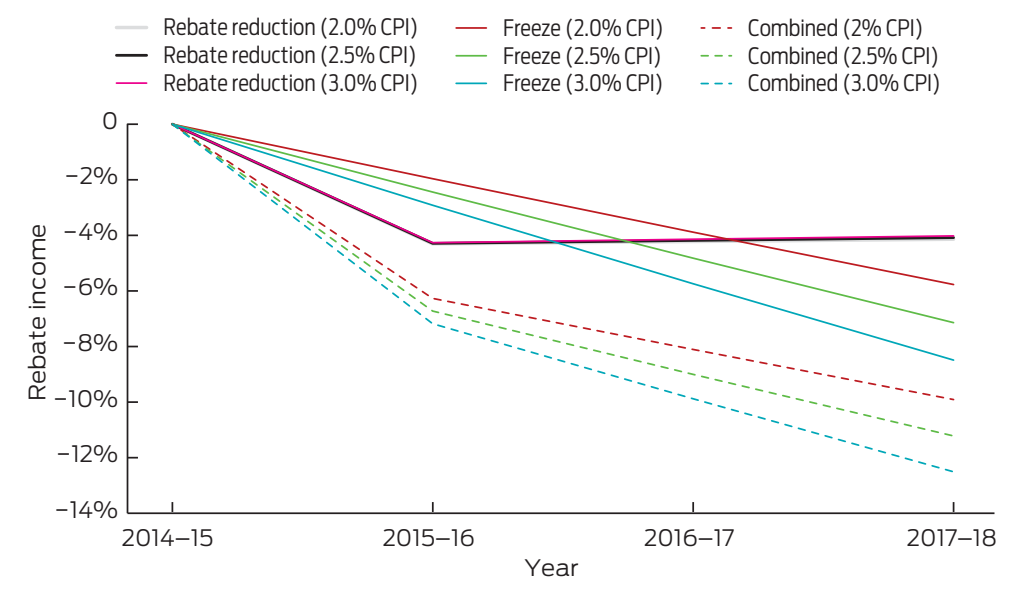

$\mathrm{CPI}=$ consumer price index

2 Copayment required for non-concessional patient consultations to maintain relative 2014-15 income with either or both of the rebate reduction and indexation freeze policies in place

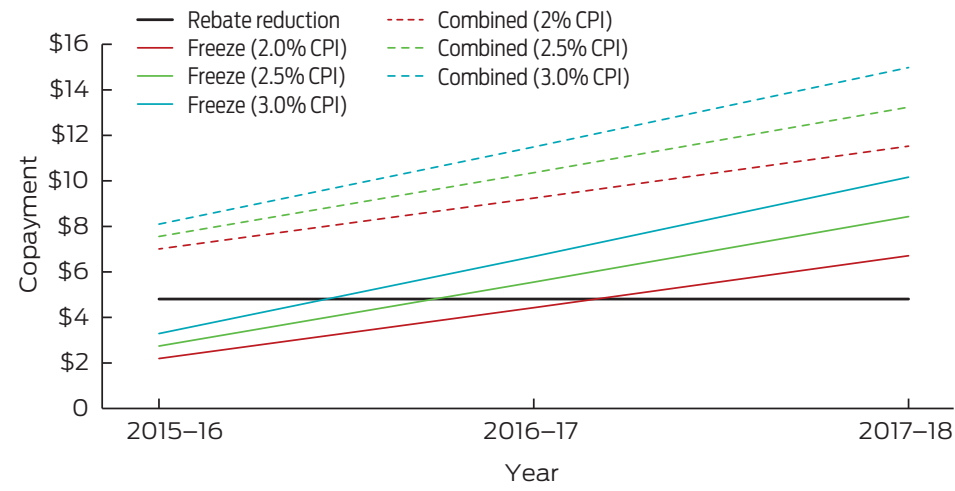

$\mathrm{CPI}=$ consumer price index

proposed, GPs would have had to charge non-concessional patients substantially more than the suggested $\$ 5$ copayment to maintain their 2014-15 relative gross income. GPs would have needed to charge a copayment of \$7-\$8 for non-concessional consultations in 2015-16 and a copayment of $\$ 12-\$ 15$ by $2017-18$ to maintain a gross income equivalent to that of 2014-15. They would have lost the equivalent of $11.2 \%$ of their rebate income from the combined effect of both policies by 2017-18. This is similar to, but more precise than, the $10.6 \%$ found by Duckett, who relied on published data. ${ }^{8}$

The now retracted rebate cut to selected items for non-concessional patients would have had a considerable immediate impact on GP income, averaging $\$ 4.81$ per consultation with non-concessional patients. However, the freeze showed a larger impact over time, increasing from a loss of $\$ 2.74$ per consultation with non-concessional patients in 2015-16 to $\$ 8.43$ in 2017-18, nearly twice the amount of the rebate cut.

The $7.1 \%$ reduction in GP rebate income by 2017-18 due to the freeze may force GPs who currently bulk bill to cover their loss by charging non-concessional patients a copayment. The freeze is therefore likely to have a greater impact on practices that serve socioeconomically disadvantaged populations. GPs practising 
in these circumstances would have to absorb the reduction in gross income, and this may not be viable.

Our estimates are conservative. We have not included in our model financial loss to GPs from:

- the freeze on other Medicare items (such as procedures, practice incentive items);

- administrative costs involved in implementing new billing systems;

- increased bad debts;

- previous indexation of schedule fees below CPI (notably since 2012 ${ }^{12}$ ); and

- lost income when a GP chooses to bulk bill any non-concessional patients facing financial hardship.

It is therefore probable that GPs will charge more than our estimates. Once GPs stop bulk billing nonconcessional patients, they may take the opportunity to charge more than what is required merely to recoup their losses. Further, there is no guarantee that copayments will only be charged to non-concessional patients.

We modelled our study on GPs who bulk billed all patients but changed to privately billing non-concessional patients after the policies were implemented. GPs who currently bulk bill concessional patients and privately bill non-concessional patients would still lose income from the schedule fee freeze for consultations with concessional patients. Using the assumptions of this study, the GP would have to charge this loss of income to nonconcessional patients over and above whatever they are already charging.

Our study has some limitations. By using the average distribution of Medicare item numbers from all BEACH GPs, we assumed that GPs who bulk bill all patients had a similar distribution of Medicare items to GPs who privately bill some or all of their patients. A recent article has suggested this is a reasonable assumption. ${ }^{13}$ We also assumed that GPs will continue billing a similar distribution of items in the future.

If both policies had gone ahead, GPs would have needed to charge significantly more than the suggested \$5 copayment for all consultations with non-concessional patients in order to maintain their 2014-15 relative gross income. Public discussion has mainly focused on the now retracted $\$ 5$ reduction, and the freeze has received far less attention. Yet, with time, it will have a greater impact: $\$ 8.43$ per non-concessional patient consultation by $2017-18$, nearly double the amount of the rebate reduction.

Our estimates are conservative and there is no way we can predict the amount GPs will charge once they are forced, for economic reasons, to introduce a copayment. The freeze will result in Medicare savings; however, patient out-of-pocket expenses will be higher than these savings because GPs will need to charge more than their lost income to recoup the additional implementation and operational costs we have discussed. The results of our study inform public debate by providing an objective measure of the minimum likely effect of the continuation of the freeze on Medicare schedule fees on general practice.

Acknowledgements: We thank the general practitioners who participated for their generosity. We also thank the BEACH team for making the BEACH program run. During the data collection period of this study, the BEACH program was funded by the Australian Government Department of Health, AstraZeneca (Australia), Novartis Pharmaceuticals Australia, bioCSL (Australia), Merck Sharp \& Dohme (Australia) and the Australian Government Department of Veterans' Affairs.

Competing interests: No relevant disclosures. Received 13 Feb 2015, accepted 10 Mar 2015.

References are available online at www.mja.com.au. 
1 Scotton RB. Medibank 1976. Australian Economic Review 1977; 10: 23-35.

2 Britt H, Miller GC, Henderson J, et al. General practice activity in Australia 2013-14. Sydney: Sydney University Press, 2014. (General practice series no. 36.) http://ses. library.usyd.edu.au/bitstream /2123/11882/4/9781743324226 ONLINE.pdf (accessed Feb 2015).

3 Biggs A. Medicare: background brief. Canberra: Parliament of Australia, 2004. http://www.aph.gov.au/ About_Parliament/Parliamentary_ Departments/Parliamentary_Library/ Publications_Archive/archive/ medicare (accessed Feb 2015).

4 Medicare Australia. 100\% Medicare rebate for GP attendances. http:// www.medicareaustralia.gov.au/ provider/incentives/files/100_per_ cent_Medicare_Rebate_for_GP attendances.pdf (accessed Feb 2015).

5 Australian Government Department of Health. Quarterly medicare statistics - March quarter 2003 to September quarter 2014 (Table 1.4). Canberra: DoH, 2014. http://www.health.gov. au/internet/main/publishing.nsf/ Content/Quarterly-Medicare-Statistics (accessed Oct 2014).

6 Bayram C, Harrison C, Miller G, Britt H. Estimated impact of proposed GP, pathology and imaging copayments for Medicare services, and the increased PBS threshold. Additional cost burden to patients from budget co-payment proposals: BEACH data. Sydney: Family Medicine Research Centre, University of Sydney, 2014. http://sydney.edu.au/medicine/fmrc/ beach/bytes (accessed Jul 2014).

7 Abbott T, Dutton P. A strong and sustainable Medicare [joint press release]. 9 Dec 2014. http://www. health.gov.au/internet/ministers/ publishing.nsf/Content/healthmediarel-yr2014-duttonili.htm (accessed Feb 2015).

8 Duckett S. \$5 Medicare rebate cut could cost patients up to $\$ 40$ more. http://theconversation.com/5medicare-rebate-cut-could-costpatients-up-to-40-more-37118 (accessed Feb 2015).

9 Australian Government Department of Health. The January 2015 Medicare Benefits Schedule. Canberra: DoH, 2015. http://www.health.gov.au/ internet/mbsonline/publishing.nsf/ Content/Downloads-2015-01 (accessed Oct 2014).
10 Australian Bureau of Statistics. Consumer Price Index, Australia, Dec 2014. Canberra: ABS, 2014. (ABS Cat. No. 6401.0.) http://www. abs.gov.au/AUSSTATS/abs@. nsf/DetailsPage/6401.0Dec\%20 2014?OpenDocument (accessed Feb 2014).

11 Reserve Bank of Australia. Inflation target. http://www.rba.gov.au/ inflation/inflation-target.html (accessed Feb 2015).

12 Australian Medical Association. Medicare funding cuts - support materials for practices. Canberra: AMA, 2014. https://ama.com.au/article/ medicare-funding-cuts-supportmaterials-practices (accessed Feb 2015).

13 De Abreu Lourenco R, Kenny P, Haas $M R$, et al. Factors affecting general practitioner charges and Medicare bulk-billing: results of a survey of Australians. Med J Aust 2015; 202: 87-90. 